\title{
Phenotypic characterisation of Australian sheep and cattle isolates of Mannheimia haemolytica, Mannheimia granulomatis and Mannheimia varigena
}

\author{
PJ BLACKALL ${ }^{a} M$ BISGAARD ${ }^{b}$ and CP STEPHEN $S^{c}$
}

\begin{abstract}
Objective To perform a comprehensive phenotypic characterisation of 35 isolates of bacteria previously identified as haemolytic Pasteurella-Actinobacillus and obtained from cattle and sheep.
\end{abstract}

Design The 35 isolates that had been obtained from Australian animals, 30 from cattle and five from sheep, were compared with reference strains of the five recognised species of the genus Mannheimia - $M$ haemolytica, $M$ glucosida, $M$ granulomatis, $M$ ruminalis and $M$ varigena.

Results Thirty-four of the isolates could be confidently assigned to three species of the genus Mannheimia. Twentynine were $M$ haemolytica, with 25 being isolated from cattle and four from sheep. All but three of the bovine $M$ haemolytica were isolated from pneumonic lungs. Of the three remaining bovine $M$ haemolytica isolates, one was obtained in pure culture from a bovine milk sample and the other two as part of a mixed flora associated with a middle ear infection of a calf suffering mucosal disease. Of the four ovine $M$ haemolytica isolates, two were isolated in pure culture from milk and two, also in pure culture, from pneumonic lungs. Three bovine isolates were identified as $M$ granulomatis - one from a tongue abscess, one from a jaw abscess and one from a lung showing suppurative bronchopneumonia. Two bovine isolates were identified as $M$ varigena - one coming from an udder and the other from a spleen. The available diagnostic records provided no information on whether these isolates were associated with a disease process. The remaining isolate was obtained from an ovine tongue abscess and could not be assigned to a recognised species within the genus Mannheimia.

Conclusion The study represents the first time that $M$ haemolytica, $M$ granulomatis and $M$ varigena have been recognised as being present in cattle and sheep in Australia. Veterinary laboratories that encounter PasteurellaActinobacillus-like organisms from cattle and sheep should attempt as complete a characterisation as possible to help improve our knowledge of the disease potential of these organsims.

Aust Vet J 2002;80:87-91

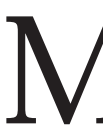

embers of the genus Pasteurella are well recognised pathogens of many species of animals. ${ }^{1} \mathrm{~T}$ he organism until recently known as [Pasteurella] haemolytica (the brackets indicate that this taxon was excluded from the genus Pasteurella sensu stricto in 19852) has long been associated with

\footnotetext{
${ }^{\mathrm{a}}$ Queensland Department of Primary Industries, Agency for Food and Fibre Sciences, Animal Research Institute, Yeerongpilly Queensland 4105 (E-mail pat.blackall@dpi.qld.gov.au)

${ }^{b}$ Department of Veterinary Microbiology, The Royal Veterinary and Agricultural University, DK-1870 Frederiksberg C, Copenhagen, Denmark

${ }^{C}$ Queensland Department of Primary Industries, Animal and Plant Health Service, Toowoomba Veterinary Laboratory, Toowoomba QLD 4350
}

respiratory disease in cattle ${ }^{3}$ and both respiratory disease and septicaemia in sheep. ${ }^{4}$ Two biotypes of $[P]$ haemolytica have been traditionally recognised - biotype $A$, consisting of isolates that ferment L-arabinose, and biotype $\mathrm{T}$, consisting of isolates that ferment trehal ose. ${ }^{5,6}$ I solates of biotype A of [P] haemolytica are associated with respiratory disease of cattle and sheep and septicaemia of young lambs while biotype T isolates have been associated with septicaemia of young adult sheep. ${ }^{4}$

D espite a general acceptance that isolates of biotype T $[P]$ haemolytica are not closely affiliated with the genus Pasteurella sensu stricto, these organisms have been classified as [P] trehalosi. ${ }^{7}$ In terms of serovars, [P] trehalosi contains [P] haemolytica serovars $3,4,10$ and $15 .^{7}$

A new genus, $M$ annheimia, has been recently proposed for the biotype $A$ isolates of $[P]$ haemolytica. ${ }^{8}$ The genus of M annheimia has five species - M haemolytica, M glucosida, M granulomatis, $M$ ruminalis and $M$ varigena. ${ }^{8}$ The bulk of what were once regarded as biotype $A[P]$ haemolytica, specifically $[P]$ haemolytica serovars $1,2,5,6,7,8,9,12,13,14$ and 16 , are now recognised as $M$ haemolytica. The isolates once recognised as [P] haemolytica serovar 11 have been reclassified as M glucosida. ${ }^{8}$ It should be noted that serotyping does not al ways result in a clear, species-specific identification. ${ }^{9}$

In the Australian context, there is considerable evidence that [P] haemolytica is a routine isolate from pneumonic bovine lungs. ${ }^{10-13}$ Taylor $^{14}$ has reported on an outbreak of fibrinous pneumonia in 331 recently weaned beef calves on two southern Q ueensland properties. While no [P] haemolytica was isolated from this outbreak, Taylor ${ }^{14}$ concluded that the clinical and necropsy findings suggested that the cause was [P] haemolytica. $M$ astitis in dairy cattle has also been associated with [P] haemolytica. ${ }^{13}$ Recently, the presence of a novel taxon of the genus $M$ annheimia, of uncertain pathogenicity, has been reported from nasal swabs of feedlot cattle..$^{15}$

In Australian sheep, there have been reports of pneumonia, mastitis ${ }^{13,16}$ and septicaemia ${ }^{17}$ associated with [P] haemolytica.

We have re-examined a collection of bacteria previously identified as Pasteurella-Actinobacillus isolates from cattle and sheep. These isolates were all identified during routine disease investigations performed at the Animal Research Institute and the Toowoomba Veterinary Laboratory between 1963 and 1997. The isolates were obtained from 29 cattle (30 isolates) and five sheep (five isolates).

\section{M aterials and methods}

Bacteria

Thirty five isol ates were studied. The available details on these isolates including the original identification is provided in Table 1. The reference strains that were used in this study were $M$ haemolytica N CTC 9380, M granulomatis AT C C 49244, M glucosida CCUG 38457, M ruminalis CCUG 38470 and M 
Table 1. Details of the cultures examined in this study.

\begin{tabular}{|c|c|c|c|c|c|c|}
\hline $\begin{array}{l}\text { Number of } \\
\text { Cultures }\end{array}$ & Original identification & Correct species & Animal species & Tissue & Other pathogens & Diagnosis \\
\hline 1 & $P$ haemolytica & $M$ granulomatis & Bovine & Lung & None & $\begin{array}{l}\text { Enteritis (lung showed suppurative } \\
\text { bronchopneumonia) }\end{array}$ \\
\hline 1 & Actinobacillus spp ${ }^{a}$ & M granulomatis & Bovine & Jaw abscess & None & Lumpy jaw \\
\hline 1 & Actinobacillus spp b & M granulomatis & Bovine & Tongue & None & Actinobacillosis tongue \\
\hline 7 & $P$ haemolytica & $M$ haemolytica & Bovine & Lung & None & Bronchopneumonia, pasteurellosis \\
\hline 6 & P haemolytica & $M$ haemolytica & Bovine & Lung & none & Pleuropneumonia, pasteurellosis \\
\hline 2 & $P$ haemolytica & $M$ haemolytica & Bovine & Lung & P multocida & Pleuropneumonia, pasteurellosis \\
\hline 1 & $P$ haemolytica & $M$ haemolytica & Bovine & Lung & $\begin{array}{l}\text { Infectious bovine } \\
\text { rhinotracheitis virus }\end{array}$ & Bronchopneumonia, pasteurellosis \\
\hline 1 & $P$ haemolytica & M. haemolytica & Bovine & Lung & Mucosal disease & $\begin{array}{l}\text { Encephalitis (Lung showed severe } \\
\text { fibrinopurulent bronchopneumonia) }\end{array}$ \\
\hline 3 & $P$ haemolytica & $M$ haemolytica & Bovine & Lung & None & Pasteurellosis \\
\hline 2 & $P$ haemolytica & $M$ haemolytica & Bovine & Middle ear & Mucosal disease & Mucosal disease \\
\hline 1 & Actinobacillus spp. & $M$ haemolytica & Bovine & Lung & None & Pneumonia \\
\hline 1 & Pasteurella spp. & $M$ haemolytica & Bovine & Lung & None & Pneumonia \\
\hline 1 & Actinobacillus spp. & $M$ haemolytica & Bovine & Milk & None & Mastitis \\
\hline 1 & $P$ mastitidis & $M$ haemolytica & Ovine & Milk & None & Mastitis \\
\hline 1 & Pasteurella spp. & $M$ haemolytica & Ovine & Lung & None & Pneumonia \\
\hline 1 & Actinobacillus lignieresii & $M$ haemolytica & Ovine & Milk & None & Mastitis \\
\hline 1 & Actinobacillus lignieresii & $M$ haemolytica & Ovine & Lung & None & Pneumonia \\
\hline 1 & Actinobacillus spp $\mathrm{a}^{\mathrm{a}}$ & $M$ varigena & Bovine & Udder & None & Unknown \\
\hline 1 & Actinobacillus spp & $M$ varigena & Bovine & Spleen & None & Kidney fibrosis \\
\hline 1 & $\begin{array}{c}\text { Actinobacillus spp }{ }^{\mathrm{a}} \\
\text { (V4619) }\end{array}$ & Mannheimia spp. & Ovine & Tongue abscess & None & Unknown \\
\hline
\end{tabular}

andicates strains previously described by Angen et al ${ }^{18}$

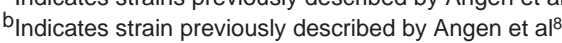

varigena CCUG 38462. All of these are type strains for their respective species.

Phenotypic characterisation

All the field isolates as well as the reference strains were subjected to a full phenotypic characterisation as previously described. ${ }^{18,19}$

\section{Case histories}

The available case histories were reviewed. In many instances, the details of the histopathogical findings were no longer available. As well, for many of the cases, only a brief summary of the original findings could be located.

\section{Results}

All 35 field isolates were Gram negative, catalase and cytochrome oxidase positive, non-motile rods that fermented glucose without gas production. The isolates had no requirements for X- or V-factors in vitro, were unable to utilise citrate, did not produce any pigment, could not grow in potassium cyanide and were negative in the methyl red and VogesProskauer tests. All the isolates could reduce nitrate without gas formation but lacked the ability to hydrolyse arginine, decarboxylate lysine and could not hydrolyse gelatin, Tween 20 or Tween 80. N one of the isolates could grow on M acC onkey agar or deaminate phenylalanine but all showed phosphatase activity. All the isolates lacked urease activity. $N$ egative reactions were also obtained in mucate (acid), malonate (base) and TSI $\left(\mathrm{H}_{2} \mathrm{~S}\right)$ tests. N one of the isolates produced acid from meso-erythritol, adonitol, D(+) arabitol, xylitol, L(-) xylose, dulcitol, D(+) fucose, $D(+)$ mannose, $L(-)$ sorbose, $D(+)$ melibiose, trehalose, $D(+)$ melezitose, $D(+)$ glycogen, inulin, $D(+)$ turanose and $\beta$ $\mathrm{N}-\mathrm{CH}_{3}$-glucosamide. All the isolates produced acid from $\mathrm{D}(-)$ ribose, D (-) mannitol D (-) fructose, D (+) galactose and sucrose. The isolates differed in a number of properties and the details of these distinguishing properties are given in Table 2, which also shows the properties of the type strains used in this study.

On the basis of the differential properties shown in Table 2, the field isolates were identified as M haemolytica (29 isolates), M granulomatis (three isolates) and $M$ varigena (two isolates). The remaining isolate could not be assigned to any currently recognised taxon in the family Pasteurellaceae.

Table 1 provides a summary of the relevant information obtained from the review of the case histories. The bovine $M$ haemolytica isolates were typically associated with bronchopneumonia and pleuropneumonia. In general, there were no other pathogens associated with these conditions. This lack of other pathogens needs to be interpreted cautiously because the isolates were obtained from routine disease investigations. In particular, it is possible that anaerobic pathogens may have been present and not detected. O ne bovine $M$ haemolytica isolate was associated with mastitis. The four ovine $M$ haemolytica isolates were associated with either mastitis (two isolates) or pneumonia (two isolates). The three M granulomatis isolates were obtained from cattle - two being associated with oral cavity abscesses and one with suppurative bronchopneumonia. The two M varigena 
Table 2. Properties of Australian isolates of Mannheimia and those of the type strains of the five recognised species of the genus Mannheimia

\begin{tabular}{|c|c|c|c|c|c|c|c|c|c|}
\hline \multirow[t]{2}{*}{ Property } & \multicolumn{2}{|c|}{ M. haemolytica } & \multicolumn{2}{|c|}{ M. granulomatis } & \multicolumn{2}{|c|}{ M. varigena } & \multirow{2}{*}{ 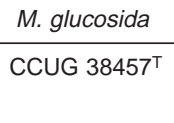 } & \multirow{2}{*}{$\begin{array}{c}\text { M. ruminalis } \\
\text { CCUG } 38470^{\top}\end{array}$} & \multirow{2}{*}{$\begin{array}{c}\text { V4619 } \\
\text { Field } \\
(1)\end{array}$} \\
\hline & $\begin{array}{l}\text { NCTC } \\
9380^{\top}\end{array}$ & $\begin{array}{l}\text { Field } \\
(30)^{\mathrm{b}}\end{array}$ & $\begin{array}{c}\text { ATCC } \\
49244^{\top}\end{array}$ & $\begin{array}{l}\text { Field } \\
\text { (3) }\end{array}$ & $\begin{array}{c}\text { CCUG } \\
38462^{\top}\end{array}$ & $\begin{array}{l}\text { Field } \\
(2)\end{array}$ & & & \\
\hline Haemolysis & $w^{c}$ & w & - & - & w & w & w & - & w \\
\hline ODC & - & - & - & - & + & + & + & - & - \\
\hline Indole & - & $v[1]^{d}$ & - & - & - & - & - & - & - \\
\hline Glycerol & - & $(+)$ & $(+)$ & $(+)$ & $(+)$ & $(+)$ & $(+)$ & - & $(+)$ \\
\hline D-Arabinose & - & $v[12]$ & w & $v[2]$ & w & $\vee[1]$ & w & $(+)$ & $(+)$ \\
\hline L-Arabinose & - & - & - & - & + & + & - & - & + \\
\hline Dextrin & + & $+/(+)$ & $(+)$ & $(+)$ & w & + & + & - & $(+)$ \\
\hline L-Fucose & + & $v[28]$ & w & $(+)$ & + & $(+)$ & + & w & + \\
\hline Glycosides $^{d}$ & - & - & + & $+/(+)$ & - & - & + & - & - \\
\hline meso-Inositol & w & $v[29]$ & w & - & $(+)$ & $(+)$ & $(+)$ & - & - \\
\hline Lactose & - & $v[24]$ & w & $(+)$ & - & $(+)$ & $(+)$ & $(+)$ & $(+)$ \\
\hline $\mathrm{L}(+)$ rhamnose & - & - & - & - & + & $(+)$ & - & - & - \\
\hline Raffinose & $(+)$ & $v[29]$ & - & - & $(+)$ & - & $(+)$ & - & $(+)$ \\
\hline D-Sorbitol & + & + & + & + & - & - & + & - & - \\
\hline D-Xylose & + & + & - & + & + & + & + & - & + \\
\hline$\alpha$-fucosidase & + & v [27] & - & - & + & - & + & - & - \\
\hline$\beta$-galactosidase & - & v [27] & + & + & + & + & + & + & + \\
\hline$\beta$-glucuronidase & + & $\vee[4]$ & + & - & - & - & - & - & - \\
\hline$\beta$-xylosidase & - & $\vee[1]$ & - & - & - & - & + & - & - \\
\hline
\end{tabular}

${ }^{\mathrm{a}}$ All isolates were Gram-negative, non-motile rods that fermented glucose without gas production. The isolates were oxidase and catalase positive, reduced nitrate to nitrite and could not grow on MacConkey agar. The isolates did not produce acid from trehalose and xylose but did produce acid from mannitol, galactose and sucrose. Further results are provided in the main text. The genus Mannheimia has been created from organisms that were previously termed biotype A [ $P$ ] haemolytica.

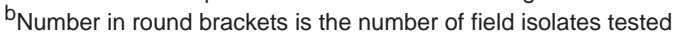

${ }^{\mathrm{C}} \mathrm{ODC}=$ ornithine decarboxylase; $\mathrm{w}=$ weak positive; + = positive within $1-2$ days; $(+)=$ positive within 14 days; $v=$ variable; - = negative

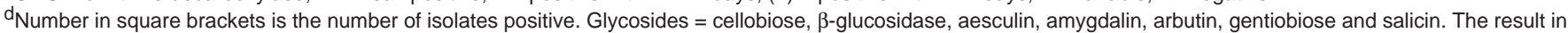
the Table is the result for all of these substrates.

isolates were from cattle. O ne isolate was obtained from the spleen of a cow showing kidney fibrosis. The other isolate was obtained from an udder but the available records provided no evidence on whether the isolate was involved in a pathological process. The remaining isolate, which could not be assigned to any of the five recognised species of the genus $M$ annheimia, was obtained from an ovine tongue abscess.

\section{Discussion}

This study has shown the problems confronting diagnostic laboratories attempting to identify members of the family Pasteurellaceae. Of the 29 isolates shown in this study to be M haemolytica, 23 were originally correctly identified - albeit in the old terminology of either [P] haemolytica (22 isolates) or [P] mastitidis. The remaining six isolates of $M$ haemolytica were originally identified as Actinobacillus lignieresii, Actinobacillus spp or Pasteurella spp. O ur finding that some of the original identifications were incorrect should not be seen as a result of any shortcomings by the original workers. The misidentifications are clear evidence of the fact that identification of bacteria that belong in the family Pasteurellaceae is a difficult task that requires considerable effort. The current study has the advantage of an extensive bank of new knowledge and additional phenotypic tests that make correct identifications much easier. A similar conclusion on the difficulties of identifying A equuli and relatives has been reported already. ${ }^{20}$

Laboratories that have a regular workload of identifying $M$ annheimia-like isolates should consider obtaining reference strains to ensure that the identification methods used in the laboratory are acceptable. Since many diagnostic laboratories in
Australia are moving to formal accreditation, this use of reference strains will become part of the quality control operations of these laboratories. Research into the devel opment and validation of molecular-based identification methods would also be of great value. Fully validated molecular methods offer considerable advantages over the complex and extended phenotypic identification schemes necessary for confident identification. Already, there are molecular identification methods for $\mathrm{H}$ aemophilus paragallinarum ${ }^{21}$ and Pasteurella multocida, 22-24 which are other members of the Pasteurellaceae.

The results of this study have shown that, like the situation in overseas countries, ${ }^{8}$ the main species of the genus $M$ annheimia associated with pneumonia and mastitis in cattle and sheep is M haemolytica. M haemolytica corresponds to [P] haemolytica serovars 1, 2, 5-9, 12-14 and $16 .{ }^{8}$ C urrently, serotyping for $M$ haemolytica is not available in Australia. This is a major limitation that prevents a more definitive understanding of bovine pneumonia - an economically important disease, particularly of feedlot cattle.

Four of the isolates included in this study, marked in Table 1, have been included in the prior studies of Angen et al.8,18 H owever, only one was included in the final publication on reclassification of the $[\mathrm{P}]$ haemolytica complex. ${ }^{8} \mathrm{D}$ ue to recent changes in the terminology of these organisms and the minor role these four isolates played in these complex prior taxonomic studies, we believe that veterinary microbiologists working in Australian veterinary laboratories may not realise that isolates of the new genus $M$ annheimia have been confirmed as being present in Australia. H ence, we have included these four previously studied isolates in the current report. 
The results of the current study, combined with the prior studies 8,18 have demonstrated the presence in Australian cattle of one of the more unusual species of the genus M annheimia M granulomatis. The three Australian isolates of $M$ granulomatis appear to be the only reported cattle isolates of this species apart from the isolates reported from Brazil. 25,26 The Brazilian bovine isolates have been associated with a progressive fibro-granulomatous panniculitis in which it has been suggested that biting insects may play a role. ${ }^{25}$ In a detailed histopathological study of both natural cases as well as experimental cases, Riet-Correra et $a^{25}$ noted the presence of small granulomas with rosettes in the centre. Riet-C orrera et al ${ }^{25}$ noted that these rosettes were very similar to those seen in actinobacillosis. The retrospective nature of our study makes it difficult for any conclusive statements to be made about the pathogenic role of the $M$ granulomatis isolates from lumpy jaw and wooden tongue cases. In particular, we cannot rule out the possibility that other agents, including anaerobes, were present and may have had a role in the disease process. N evertheless, our results indicate that laboratories culturing cases of lumpy jaw and wooden tongue should perform the level of phenotypic characterisation necessary to confidently identify any Pasteurella-like organisms isolated

Two of the Australian isolates were first obtained in the 1960s, considerably predating the Brazilian description of panniculitis. These 1960 Australian isolates were recognised as being different from any known organism of the time, hence they were termed Actinobacillus species. $M$ granulomatis can be readily separated from both $M$ haemolytica and $A$ lignieresi by phenotypic characterisation, the latter organism being the species normally associated with granulomatous lesions of the bovine tongue. Veterinary laboratories isolating an Actinobacillus-like organism from these types of oral lesions should attempt identification to the species level.

O ne of our isolates of $\mathrm{M}$ granulomatis was obtained in pure culture from a bovine lung with suppurative bronchopneumonia. This appears to be the first time that $M$ granulomatis has been reported in a situation strongly suggesting a role in a pathogenic process of the bovine lung. In contrast, there is a strong association with bronchopneumonia for the leporine isolates of M granulomatis. ${ }^{19,27}$ As our isolate was originally identified as $[P]$ haemolytica, it is possible that other evidence of the association between bovine bronchopneumonia and $M$ granulomatis has been missed. It is important that laboratories investigating bovine respiratory disease attempt as complete an identification of bacterial isolates as possible. 0 ver time, this level of identification should result in an accumulation of evidence that will help clarify the role of $M$ granulomatis in bovine bronchopneumonia.

Two of the isolates in this study were identified as M varigena. 0 ne of these isolates has been characterised previously as [P] haemolytica biogroup 6.18 $\mathrm{M}$ varigena isolates form two biovars - biovar 1 are ornithine decarboxylase positive and are typically isolated from cattle whereas biovar 2 are ornithine decarboxylase negative and are typically isolated from pigs. ${ }^{8}$ Bovine isolates of $M$ varigena have been associated with disease conditions such as pneumonia, mastitis and septicaemia as well as being isolated from non-sterile sites such as the rumen, the oral cavity and the intestine. ${ }^{8}$ The two Australian isolates do not have a detailed available history, although the spleen isolate does not seem to have had a role in any pathogenic process. Careful speciation of $[P]$ haemolytica-like isolates into the new $\mathrm{M}$ annheimia species is required before any overall assessment can be made of the role of $M$ varigena in bovine disease in Australia.

In summary, this study has confirmed the presence of three of the new species of the genus M annheimia in Australian cattle and sheep - M haemolytica, M granulomatis and M varigena. The detailed identification table provided in this study (Table 2) should assist laboratories in this task of extended characterisation.

\section{Acknowledgments}

The contribution of the microbiologists and pathologists who performed the initial pathological, histopathological and microbiological studies on the 15 isolates from the 1960s and 1970s used in this study is gratefully acknowledged.

\section{References}

1. Bisgaard M. Ecology and significance of Pasteurellaceae in animals. $\mathrm{Zbl}$ Bakteriol 1993;279:7-26.

2. Mutters R, Ihm P, Pohl S, Frederiksen W, Mannheim W. Reclassification of the genus Pasteurella Trevisan 1887 on the basis of deoxyribonucleic acid homology, with proposals for the new species Pasteurella dagmatis, Pasteurella canis, Pasteurella stomatis, Pasteurella anatis, and Pasteurella langaa. Int J Syst Bacteriol 1985;35:309-322.

3. Frank GH. Pasteurellosis of cattle. In: Adlam C, Rutter JM, editors. Pasteurella and Pasteurellosis. Academic Press, London, 1989:197-222.

4. Gilmour NJL, Gilmour JS. Pasteurellosis of sheep. In: Adlam C, Rutter JM, editors. Pasteurella and Pasteurellosis. Academic Press, London, 1989;223262.

5. Smith GR. Isolation of two types of Pasteurella haemolytica from sheep. Nature (Lond) 1959;183:1132-1133.

6. Smith GR. The characteristics of two types of Pasteurella haemolytica associated with different pathological conditions in sheep. J Path Bacteriol 1961;81:431-440

7. Sneath PH, Stevens M. Actinobacillus rossii sp. nov., Actinobacillus seminis sp. nov., nom. rev., Pasteurella bettii sp. nov., Pasteurella lymphangitidis sp. nov, Pasteurella mairi sp. nov., and Pasteurella trehalosi sp. nov. Int J Syst Bacteriol 1990;40:148-153.

8. Angen $\varnothing$, Mutters R, Caugant DA, Olsen JE, Bisgaard M. Taxonomic relationships of the [Pasteurella] haemolytica complex as evaluated by DNA-DNA hybridizations and 16S rRNA sequencing with the proposal of Mannheimia haemolytica gen. nov., comb. nov., Mannheimia granulomatis comb. nov., Mannheimia glucosida sp. nov., Mannheimia ruminalis sp. nov. and Mannheimia varigena sp. nov. Int J Syst Bacteriol 1999;49:67-86.

9. Angen $\varnothing$, Quirie M, Donachie W, Bisgaard M. Investigations on the species specificity of Mannheimia (Pasteurella) haemolytica serotyping. Vet Microbiol 1999;65:283-290.

10. Stephens CP, Blackall PJ, Wade LK, Lowe LB. In-vitro antibacterial properties of tilmicosin against Australian isolates of Pasteurella haemolytica and Pasteurella multocida from cattle. Aust Vet J 1993;70:391-392.

11. Blackall PJ, Pahoff JL, Stephens CP, Darvill FM. In vitro activity of ceftiofur against Australian isolates of the family Pasteurellaceae associated with respiratory disease in cattle and pigs. Aust Vet $J$ 1996;74:71.

12. Irwin MR, McConnell S, Coleman JD, Wilcox GE. Bovine respiratory disease complex: a comparison of potential predisposing and etiologic factors in Australia and the United States. J Am Vet Med Assoc 1979;175:1095-1099.

13. Links IJ, Searson JE, Godwin J, Glastonbury JR, Philbey AP, Matthews LM. Pasteurella multocida and Pasteurella haemolytica infections in ruminants and pigs in southern New South Wales. In: Patten BE, Spencer TL, Johnson RB, Hoffmann D, Lehane L, editors. Pasteurellosis in Production Animals. Australian Centre for International Agricultural Research, Canberra, 1992:108-111.

14. Taylor LF. Outbreak of fibrinous pneumonia in recently weaned beef calves in southern Queensland. Aust Vet J 1998:76:21-24.

15. Blackall PJ, Angen $\varnothing$, Fegan N, Blackall LL, Mutters R, Bisgaard M. Characterisation of a novel Mannheimia sp from Australian feedlot cattle. Aust Vet J 2001;79:634-639.

16. Kabay MJ, Ellis TM. Intraperitoneal inoculation of ewes with an autogenous vaccine to prevent mastitis due to Pasteurella haemolytica. Aust Vet $J$ 1989:66:342-343

17. Mackie JT, Barton M, Hindmarsh M, Holsworth I. Pasteurella haemolytica septicaemia in sheep. Aust Vet $J$ 1995;72:474.

18. Angen $\varnothing$, Aalbaek B, Falsen E, Olsen JE, Bisgaard M. Relationships among strains classified with the ruminant Pasteurella haemolytica-complex using quantitative evaluation of phenotypic data. Zbl Bakteriol 1997;285:459-479.

19. Angen $\varnothing$, Olsen JE, Bisgaard M. Further studies of the relationships among 
strains classified as taxon 15, taxon 18, taxon 20, (Pasteurella) granulomatis or the (Pasteurella) haemolytica-complex in ruminants using quantitative evaluation of phenotypic data. Zbl Bakteriol 1997;286:317-332.

20. Blackall PJ, Bisgaard M, McKenzie RA. Characterisation of Australian isolates of Actinobacillus capsulatus, Actinobacillus equuli, Pasteurella caball and Bisgaard Taxa 9 and 11. Aust Vet J 1997;75:52-55.

21. Chen X, Miflin JK, Zhang P, Blackall PJ. Development and application of DNA probes and PCR tests for Haemophilus paragallinarum. Avian Dis 1996;40:398-407.

22. Townsend KM, Frost AJ, Lee CW, Papadimitriou JM, Dawkins JS. Development of PCR assays for species- and type-specific identification of Pasteurella multocida isolates. J Clin Microbiol 1998;36:1096-1100.

23. Kasten RW, Carpenter TE, Snipes KP, Hirsch DC. Detection of Pasteurella multocida-specific DNA in turkey flocks by use of the polymerase chain reaction. Avian Dis 1997;41:676-682

24. Miflin JK, Blackall PJ. The development of a 23S rRNA based PCR for Pasteurella multocida. Lett Appl Microbiol 2001;33:216-221.

25. Riet-Correra F, Méndez MC, Schild AL, Ribeiro GA, Almeida SM. Bovine focal proliferative fibrogranulomatous panniculitis (Lechiguana) associated with Pasteurella granulomatis. Vet Pathol 1992;29:93-103.

26. Ribeiro GA, Carter GR, Frederiksen W, Riet-Correra F. Pasteurella haemolytica-like bacterium from a progressive granuloma of cattle in Brazil. $J$ Clin Microbiol 1989;27:1401-1402.

27. Devriese LA, Bisgaard M, Hommez J, Uyttebroeck E, Ducatelle R, Haesebrouck F. Taxon 20 (Fam. Pasteurellaceae) infections in European brown hares (Lepus europaeus). J Wildl Dis 1997;27:685-687.

(Accepted for publication 2 July 2001)

\section{Comparison of infectivity of Eimeria tenella oocysts maintained at 4,12 or $28^{\circ} \mathrm{C}$ for up to 10 months}

\author{
PJ JESTON \\ GW BLIGHT \\ GR ANDERSON \\ JB MOLLOY \\ WK JORGEN SEN
}

\author{
Agency for Food and Fibre Sciences \\ D epartment of Primary Industries \\ Animal Research Institute \\ Locked Mail Bag N 0. 4 \\ M oorooka, Q ueensland 4105
}

occidiosis is an economically important protozoan disease of poultry caused by members of the parasitic genus Eimeria (Coccidia: Eimeriidae). ${ }^{1}$ Current methods for coccidiosis control in the Australian poultry industry depend on incorporation of anticoccidial agents into feed or water. The major drawbacks of chemical control include the growing problem of drug-resistance and the increasingly complex control programs required. An alternative method of coccidiosis control, which avoids the problems associated with drug resistance, is use of live attenuated vaccines either alone or in conjunction with an integrated chemical control program.

A requirement for both commercial production and distribution of live vaccines is an efficient storage method that maintains the infectivity of vaccine batches for an extended period. A long storage time is desirable as this allows larger batches to be produced with a reduction in costs per dose. The currently accepted method for storing Eimeria oocysts is to maintain the parasites at $4^{\circ} \mathrm{C}$ in $2 \%$ potassium dichromate or in sterile media. ${ }^{2-6}$ T here are few published reports ${ }^{7}$ examining the rate of decline of infectivity of poultry Eimeria oocysts stored over time or comparing different storage temperatures. The aim of this experiment was to determine which of 4,12 or $28^{\circ} \mathrm{C}$ is the best storage temperature for Eimeria tenella oocysts.

$M$ ale Webster strain W hite Leghorn chickens were used for all experimental work. They were reared until 4 weeks old under Eimeria-free conditions in positive pressure isolators supplied with $\mathrm{H}$ EPA filtered air.

D uring infectivity trials, birds were housed in suspended wire cages in a controlled environment room maintained at $25^{\circ} \mathrm{C}$ with light from $0600 \mathrm{~h}$ to $2200 \mathrm{~h}$ daily. Feed and water were available continuously. Feed was custom formulated without coccidiostats, heat treated during pelleting and stored at $-20^{\circ} \mathrm{C}$ for a minimum of 5 days to ensure freedom from viable Eimeria. All equipment used was sterilised by either autoclaving or heat treatment at $90^{\circ} \mathrm{C}$ for $4 h .8$ Faeces were collected in sterilised trays suspended under each cage.

At the start of the experiment, one pooled batch of sporulated oocysts was produced from faeces collected from six birds inoculated with a precocious vaccine strain of $E$ tenella ( $D$ arryll strain). Two days after sporulation, 180 vials (5 mL) were prepared each containing 500 oocysts in $1 \mathrm{~mL}$ aliquots of $2 \%$ potassium dichromate solution. The contents of the vials were either immediately inoculated by gavage into chickens (time zero) or used in four infectivity trials involving storage for 2,4 , 6 or 10 months at 4 (commercial refrigerator, range $2.5-7^{\circ} \mathrm{C}$ ), 12 or $28^{\circ} \mathrm{C}$ (laboratory incubators, range $\pm 1^{\circ} \mathrm{C}$ ) (Table 1 ).

The design for measuring oocyst production from oocysts inoculated at time zero was 12 replicate cages. The experimental design of each of the four infectivity trials for stored oocysts was a randomised blocks layout of 12 cages, with four replicate cages for each of the three storage temperature treatments $(4,12$ or $28^{\circ} \mathrm{C}$ ). The experimental unit was a cage of three birds.

Table 1 Mean oocyst production per bird after inoculation with 500 E tenella oocysts, either freshly sporulated or stored for various times at three different temperatures.

\begin{tabular}{cccccc}
\hline $\begin{array}{c}\text { Storage } \\
\text { temperature } \\
{ }^{\circ} \mathrm{C}\end{array}$ & 0 & 2 & 4 & 6 & 10 \\
\cline { 2 - 6 } Nil Storage & 134.2 & & & \\
& $(24.1)$ & & & & \\
4 & & $141.9^{\mathrm{AB}}$ & $79.5^{\mathrm{A}}$ & $58.8^{\mathrm{B}}$ & $0^{\mathrm{B}}$ \\
& & $(28.6)$ & $(5.0)$ & $\left(2.0^{\circ}\right.$ & $(0)$ \\
12 & $170.5^{\mathrm{A}}$ & $104.1^{\mathrm{A}}$ & $121.1^{\mathrm{A}}$ & $78.4^{\mathrm{A}}$ \\
& & $(49.6)$ & $(11.3)$ & $(17.8)$ & $(4.8)$ \\
28 & & $110.0^{\mathrm{B}}$ & $0^{\mathrm{B}}$ & $0^{\mathrm{C}}$ & $\mathrm{ND}$ \\
& & $(13.3)$ & $(0)$ & $(0)$ & \\
\hline
\end{tabular}

Mean oocyst production is cube root transformed; oocyst numbers $\left(\times 10^{-5}\right)$ are given as back transformed means in parenthesis.

Means within columns followed by different superscript letters are significantly different at the $5 \%$ level.

LSD (two-tailed $t$ test, $\mathrm{P}=0.05)=32.7$ for comparing storage temperature means, at the same storage time only, on the transformed scale.

LSD (one-tailed $t$ test, $\mathrm{P}=0.05)=27.2$ for comparisons involving storage temperature treatment means versus zero oocyst production, at the same storage time only, on the transformed scale.

ND not done. 